\title{
Transformer Differential Protection Using Wavelet Packet Transform
}

\author{
Jitendra Singh Chandra ${ }^{1}$, Amit Goswami ${ }^{2}$ \\ ${ }^{1} \mathrm{M}$ Tech Scholar, Department of Electrical and Electronics Engineering, Disha Institute of Management \& Technology Raipur (C.G.) \\ ${ }^{2}$ Assistant Professor, Department of Electrical and Electronics Engineering, Disha Institute of Management \& Technology Raipur (C.G.)
}

\begin{abstract}
When a transformer is energized the magnetizing inrush current occurs in the primary side. The magnitude of this inrush current may be very high upto ten times of transformer rated current which causes malfunction of differential protection system. Therefore, it is necessary to differentiate inrush current from faults. In this paper, a new approach of discrimination between fault currents and inrush current is proposed based on wavelet packet transform (WPT). This method efficiently helps in the development of differential protective relay to automatically detect and differentiate internal incipient faults from magnetizing inrush currents. The proposed approach is tested for signal tripping using MATLAB for data collected from Electromagnetic Transient Program/ Alternative Transient Program (EMPT/ATP) model of three phase power transformer for different cases that included normal operation, inrush current and internal fault currents. Results obtained from MATLAB clearly show that the proposed approach facilitates the accurate discrimination between inrush and fault currents in transformer differential protection. It prevents false tripping of differential relay due to inrush current.
\end{abstract}

Keywords: Magnetizing Inrush current, differential protection, wavelet packet transform (WPT), fault current, Electromagnetic transient program (EMTP).

\section{Introduction}

Power Transformers are very important and essential part of power system because it has ability to change the level of voltage and current, which enables to transmit and distribute electric power at economical and suitable manner[2]. It is very important that transformer perform its function properly in normal condition. Transformer protection is of critical importance in power systems and is always a challenging problem for protection experts and engineers. Since minimization of frequency as well as duration of unwanted outages, is very desirable, this is a high demand enforced on power transformer protective relays; this includes the requirements of dependability associated with normaloperations, security associated with no wrong tripping, and operating speed associated with short fault clearing time[1].

Transformer energization is a regular and essential operation in an electric power system. This process often results in the transformer drawing large inrush current, which finally decays down to a small magnetizing current. The time it takes inrush current to decay depends on the circuit parameters i.e. resistance and reactance of the circuit, including the magnetizing reactance of transformer. Since the magnetizing inductance of transformer is high, the inrush current may take a long time to reach its steady state value.

The inrush current affects voltage and causes a temporary voltage drop for small time duration due to impedance of the network between the energized transformer and the sources. If the source impedance is high or short circuit MVA available at the transformer bus is low the resulting voltage drop can be significant. The voltage drop comes low with decay of the inrush[5]. This inrush current also causes false tripping operation of differential relays with is a major problem at the time of transformer energization.
Most of the conventional power transformer protection relays employ the harmonic restrain analysis approach to identify the type of the current that flows in the protected transformer. The main idea of the harmonic restraint type differential relays is to extract the fundamental harmonic (1st), the second harmonic (2nd) and sometimes the fifth harmonic (5th) and to compare the ratios of the second and fifth harmonics with 1 st to a predefined set value. [3] Sometimes a time delay technique is also employed to protect the unwanted operation and false tripping of differential relay at the time of switching of transformer [2].

The wavelet transform and wavelet analysis have emerged as a powerful tool at present for signal processing in different applications, in particular now for power electronics and power system applications. The transient characteristics of wavelets may be employed to find out accurate and effective analysis of signals with complex time-frequency structure. There are different types of wavelets, and they are classified according to their characteristics of the generated basis functions.

Wavelet families are classified as, biorthogonal, orthogonal and nonorthogonal. B-Spline is an example of biorthogonal while Coiflet, Daubieches, Meyer and Symlet are examples of orthogonal wavelet families. Gaussian, Morlet and Mexican Hat belongs to the nonorthogonal wavelet families[3].

This paper proposes a new algorithm based on the Wavelet packet transform to diagnose internal fault, normal operation and magnetizing inrush current. The application of wavelet packet transform (WPT) on any signal produces details and approximation at each level of resolution. The value of the measured differential current samples of the second level details is compared to zero, and the result of the comparison is used to distinguish between the fault and non fault currents.

\section{Volume 4 Issue 12, December 2015}




\section{Wavelet Packet Transform (WPT)}

WPT is one type of wavelet-based signal processing that offers a detailed localized frequency-time analysis of discrete time signals (DT). This analysis is taken as a result of successive time localization of frequency sub bands generated by a tree of low-pass filtering and high-pass filtering operations. As a result, there is higher frequency resolution, while the time resolution goes on reducing with increasing the number of used filter banks. Starting with the DT signal $x[n]$ of length $N$, the first level $m=1$ decomposition produces two sub band DT signals as

$$
\begin{aligned}
& \mathrm{a}^{1}[n]=\sum_{k=0}^{N-1} \mathrm{~g}[\mathrm{k}] \mathrm{x}[\mathrm{n}-\mathrm{k}] \\
& \mathrm{d}^{1}[n]=\sum_{k=0}^{N-1} \mathrm{~h}[\mathrm{k}] \mathrm{x}[\mathrm{n}-\mathrm{k}]
\end{aligned}
$$

where $a^{1}[n]$ and $d^{1}[n]$ are the first-level approximations and the first level details respectively. $k$ is a constant, and $g[n]$ and $h[n]$ are the low-pass filter and the high-pass filter respectively, which are associated with the used wavelet function. To increase the frequency resolution and ensuring the time localization of each frequency subband, the outputs of both the filters i.e. Low Pass Filter (LPF) and High Pass Filter (HPF) are downsampled by two at the end of each stage of filtering. The second-level decomposition $(\mathrm{m}=2)$ produces following four subbands

$$
\begin{aligned}
\mathrm{aa}^{2}[n]= & \sum_{k=0}^{\frac{W}{z}-1} \mathrm{~g}[\mathrm{k}] \mathrm{a}^{2}\left[\frac{\mathrm{N}}{2}-1\right] \\
\mathrm{ad}^{2}[\mathrm{n}] & =\sum_{k=0}^{\frac{W}{z}-1} \mathrm{~h}[\mathrm{k}] \mathrm{a}^{2}\left[\frac{\mathrm{N}}{2}-1\right] \\
\mathrm{da}^{2}[n]= & \sum_{k=0}^{\frac{N}{2}-1} g[k] \mathrm{d}^{1}\left[\frac{\mathrm{N}}{2}-1\right] \\
\mathrm{dd}^{2}[n]= & \sum_{k=0}^{\frac{N}{2}-1} \mathrm{~h}[\mathrm{k}] \mathrm{d}^{1}\left[\frac{\mathrm{N}}{2}-1\right]
\end{aligned}
$$

where $d d^{2}[n]$ represents the highest frequency subband of the second level of the WPT decomposition[2][4]. Fig. 1 shows the successive Low pass filtering (LPF) and High pass filtering (HPF) stages that implement the WPT decomposition.

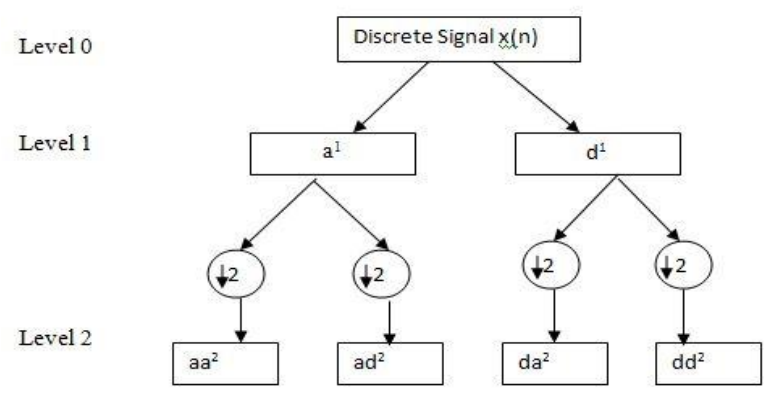

Figure 1: Decomposing a discrete signal $x[n]$ using a twolevel WPT

\section{WPT-Based Disturbance Detection}

The waveforms associated with fast electromagnetic transients (EMT) are typically non-periodic signals which contain high frequency oscillations as well as localized impulses superimposed on the power frequency and its harmonics. These create a problem for discrete Fourier transform (DFT), because its use assumes a periodic signal and that the representation of a signal by the DFT is best reserved for periodic signals. As power system disturbances are subjected to transient and non-periodic components, the DFT alone is not an adequate technique for signal analysis. If a signal is altered in a localized time instant, the entire frequency spectrum can be affected[2].

The WT is a powerful signal processing tool used in power system. The WT allows time localization of different frequency components of a given signal. As a result, both frequency and time resolution of the resulting transform will be prior fixed in the WT, the analyzing functions, which are called wavelets, adjust their time-widths to their frequency in such a way that, the high frequency wavelets will be very narrow and low frequency ones will be broader. So WT can separate transient components in the upper frequency isolated in a shorter part of power frequency cycle. The ability of the WT to focus on short time intervals for highfrequency components and long intervals for low-frequency components improves the analysis of signals with localized impulses and oscillations. For this reason, wavelet decomposition is ideal for studying transient signals and obtaining a much better current characterization and a more reliable discrimination.

Wavelet Packet Transform (WPT) is generated by analyzing the input current signal to a tree of low pass and high pass filtering operations as shown in figure 1. Down-sampling by 2 is taking place between any two successive levels. It is clear from the figure that the frequency bandwidth of the levels band decreases with the growing of the level number, which means that the frequency resolution becomes higher by the increase of the level number. However, the higher the number of the levels the higher the processing time of the signal. The increase of the processing time is a problem when the number of the levels needed is high.

It is obvious from the figure that by decomposing the signal $f(n)$ the low and high frequencies, the low frequency of the first level is the approximation $a^{I}[n]$ of the signal and the high frequency is the details $d^{l}[\mathrm{n}]$ of the input signal. Where the superfix 1 and 2 refers to the 1 st and 2 nd level of the 


\section{International Journal of Science and Research (IJSR) \\ ISSN (Online): 2319-7064}

Index Copernicus Value (2013): 6.14 | Impact Factor (2014): 5.611

wavelet decomposition respectively. Each part in the first level is also decomposed in the same manner into two parts of approximations and details. Therefore, it will produce four sub-bands by using the same filters used in the first level of decomposition. These basis functions are generated from one base function called the mother wavelet. The first and second level sub-bands are obtained using two filters (low and high).

\section{Magnetizing Inrush Current and Fault current}

After disconnecting a power transformer from the supply, some magnetizing flux is present in the core while reelectrifying the transformer and connecting it to the network, so an initial surge of current is created in primary winding. This current resumes until DC component of flux is completely removed.

After cutting out the transformer from the source, some magnetizing flux still remains in the core. After electrifying the transformer and connecting with network, the initial surge of current that produces when voltage is first applied to the primary winding with no load connected is known as magnetizing inrush current. This inrush current has transient nature appears in primary can be ten times higher than rated current and causes malfunction of relay.Inrush current also causes electromechanical stress between windings, unusual voltage distribution between windings and appearance of very high current in windings[6].

The proposed method of discriminating internal fault from inrush current is based on the different behavior of these waveforms following the disturbance. Since the magnetizing inrush current corresponds to the power transformer core saturation, the magnetizing inrush current has a conical shape (non-sinusoidal); in other words magnetizing inrush current at the switching time increases very slowly; as time increases its slope increases. Shape of waveform due to magnetizing inrush current is generally unidirectional. However, when a fault occurs, the differential current contains higher slope compared with the starting of the magnetizing inrush current, and its slope decreases as time increases. Shape of waveform for fault current is generally cosinusoidal or sinusoidal. Fig. 2 shows the abovementioned features. Since this type of features occur from the different nature of the currents and parameters of power transformer and the connected power system has no influence on it, so this type of features may be used as the basis of differentiating the fault current from the inrush current [2].

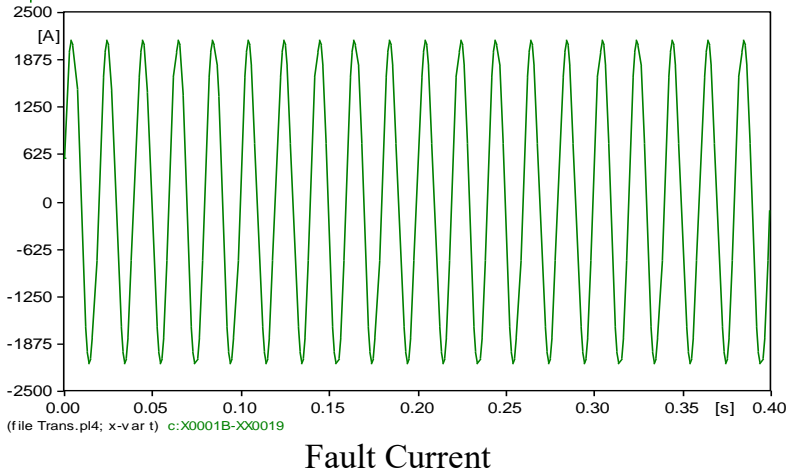

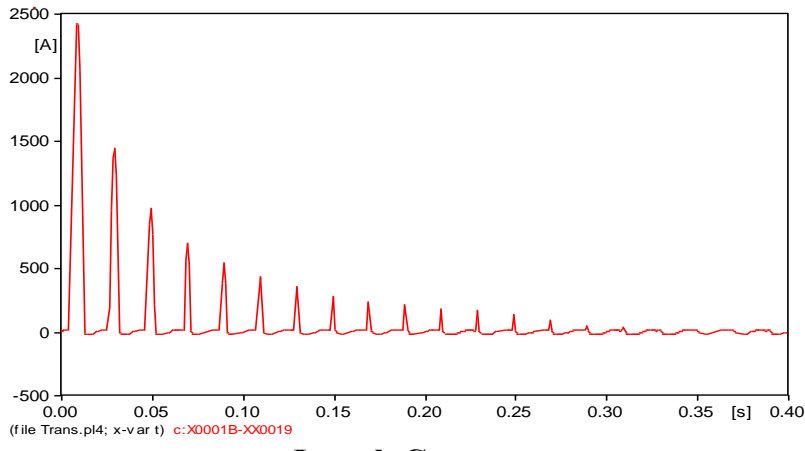

Inrush Current

Figure 2: Different behavior of fault current and Inrush current

\section{WPT based Transformer Differential protection}

The Wavelet Packet Transform (WPT) algorithm for powertransformer protection can be realized by evaluating the coefficients of the WPT details and comparing their values in the second-level highest frequency subband to zero. The evaluation of the WPT coefficients can be achieved by extracting the second-level highest frequency subband $d d^{2}[n]$ component of the transformer differential currents. The required digital HPFs for extracting the second-level highest frequency subband $d d^{2}[n]$ component are separated by a downsampling stage to increase the frequency resolution. The WPT-based transformer differential protection can be implemented using the following steps [2][4].

- Step 1: Initialize the samples' counter $n=0$.

- Step 2: Read one sample from each of the three-phase differential currents $I a, I b$, and $I c$ and store these samples in three vectors of length $N$ as $I_{d a}[N], I_{d b}[N]$, and $I_{d c}[N]$.

- Step 3: Perform the first-level high-pass filtering for $\mathrm{I}_{\mathrm{da}}[\mathrm{N}], \mathrm{I}_{\mathrm{db}}[\mathrm{N}]$, and $\mathrm{I}_{\mathrm{dc}}[\mathrm{N}]$ (disturbance detection) as

$$
\begin{aligned}
& \mathrm{d}_{\mathrm{a}}{ }^{1}[\mathrm{n}]=\sum_{\mathrm{k}=0}^{\mathrm{N}-1} \mathrm{~h}[\mathrm{k}] \mathrm{I}_{\mathrm{da}}[\mathrm{N}-\mathrm{k}] \ldots \ldots \ldots \ldots \ldots \ldots . .7
\end{aligned}
$$

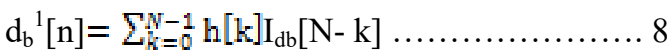

$$
\begin{aligned}
& \mathrm{d}_{\mathrm{c}}{ }^{1}[\mathrm{n}]=\sum_{\mathrm{k}=0}^{\mathrm{N}-1} \mathrm{~h}[\mathrm{k}] \mathrm{I}_{\mathrm{dc}}[\mathrm{N}-\mathrm{k}] \ldots \ldots \ldots \ldots \ldots \ldots . . . \ldots
\end{aligned}
$$

- Step 4: Downsample $d_{a}^{1}[n], d_{b}^{1}[n]$, and $d^{1}{ }_{c}[n]$ by two.

- Step 5: Perform the second-level high-pass filtering for the downsampled by two versions of $d^{1}{ }_{a}[n], d^{1}{ }_{b}[n]$, and $d^{1}{ }_{c}[n]$ (disturbance classification) to determine $d d^{2}{ }_{a}[n], d d^{2}{ }_{b}[n]$, and $d d^{2}{ }_{c}[n]$ using equation (6)

- Step 6: Declare FAULT and initiate a trip signal

IF

$$
\begin{aligned}
& \sum_{k=0}^{\frac{N}{2}-1} d d_{a}^{2}[k]>0 \\
& \text { or } \\
& \sum_{k=0}^{\frac{N}{2}-1} d d_{b}^{2}[k]>0 \\
& \text { or } \\
& \sum_{k=0}^{\frac{N}{2}-1} d d_{c}^{2}[k]>0 \\
& \text { ELSE: } n=n+1 . \\
& \text {-Step 7: If } n \geq N \text {, then } n=0 .
\end{aligned}
$$




\section{International Journal of Science and Research (IJSR) \\ ISSN (Online): 2319-7064 \\ Index Copernicus Value (2013): 6.14 | Impact Factor (2014): 5.611}

- Step 8: Go To Step 2.

Fig. 3 shows the schematic diagram for the Wavelet Packet Transform (WPT) based transformer differential protective relay. The WPT-based differential relay is supplied by threephase differential currents to detect and classify disturbances that may result from internal faults and inrush currents. These detection and classification functions are carried through one by one high-pass filtering of the sampled versions of the three-phase differential currents. For implementation of this proposed method a simulation model is prepared.

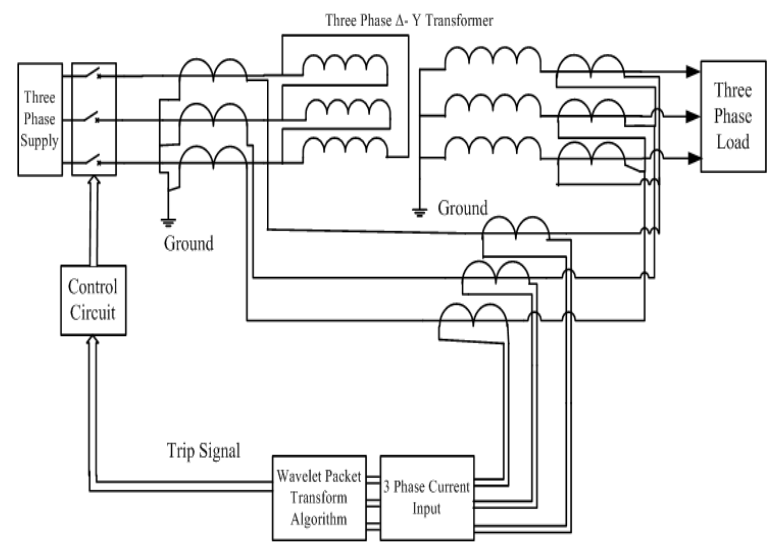

Figure 3: Schematic diagram for the WPT based transformer differential protective relay[2][4].

Fig. 4 shows EMTP simulation model for proposed method. Data for different operating conditions are collected from this simulation model which is used in MATLAB program for the analysis of relay tripping operations. In this paper following cases are presented.

1) Normal operation

2) Magnetizing Inrush current, Unloaded

3) LG Fault during magnetizing Inrush current

4) Secondary LG fault, Loaded

5) Secondary LL fault, Loaded

6) Secondary LLLG fault, Loaded

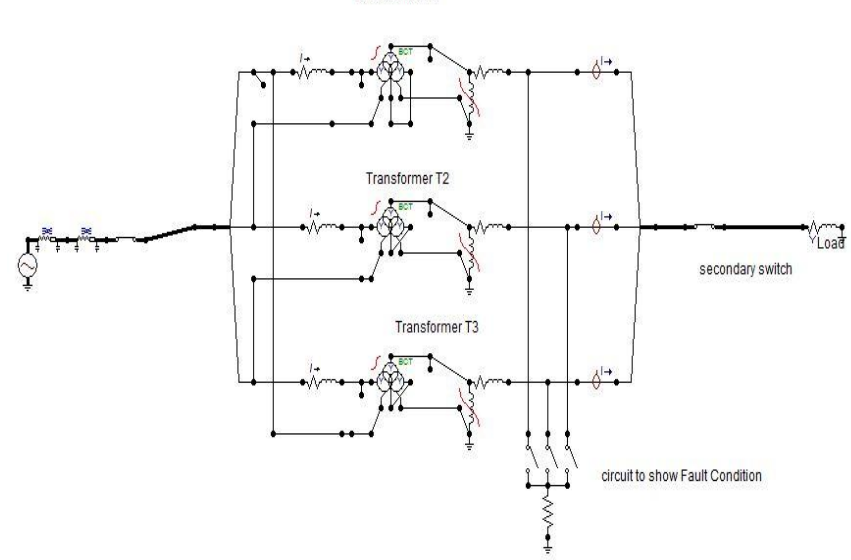

Figure 4: Simulation circuit of proposed WPT based differential protection

\section{Result and Discussion}

Wavelet Packet Transform gives very accurate and fast response. We can observe the tripping response for Normal condition, Inrush condition and different fault conditions. The Improvement of performance of differential protection can be clearly seen by the output waveforms of the WPT based differential Relay.

Case 1 Normal operation

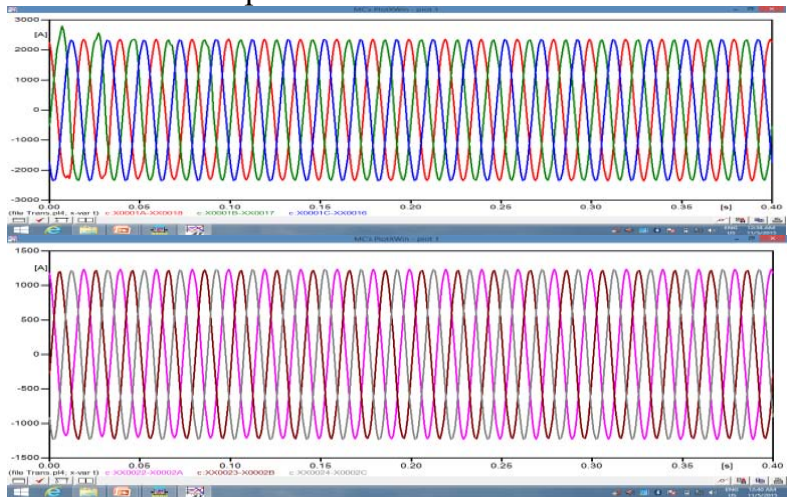

Figure 5: Input and Output Current waveform for Normal Operating Condition
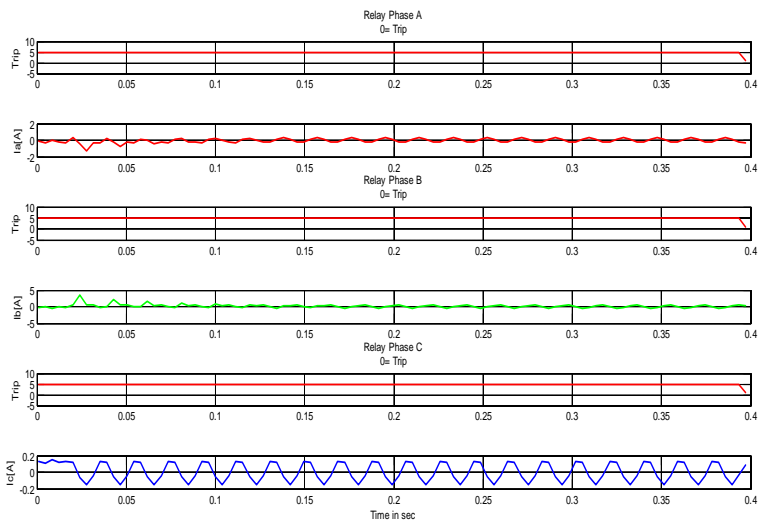

Figure 2: Relay Tripping Status for Normal operating condition

Fig 5 shows input and output current waveform for normal operation. It can be clearly seen that almost equal current is flowing in all the three phase. Fig 6 shows relay tripping status for this condition in which all relays are in high position and there is no tripping which is desirable for normal operation.

Case 2 magnetizing inrush current, Unloaded

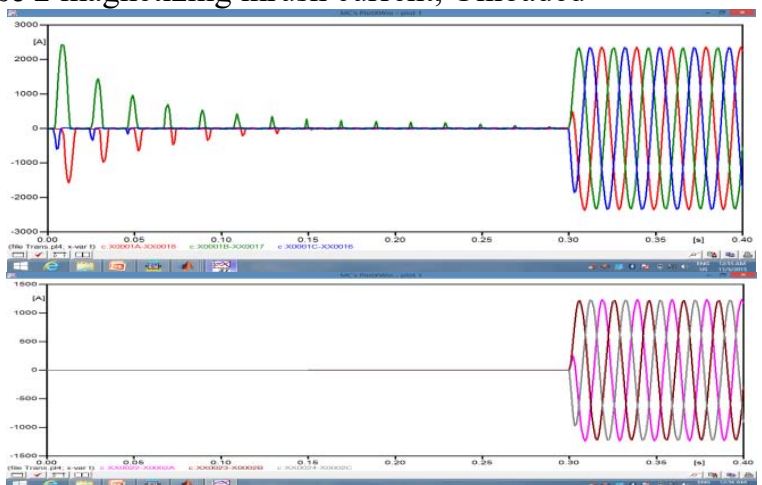

Figure 7: Input (Magnetizing Inrush Current) and Output Current waveform

\section{Volume 4 Issue 12, December 2015}


International Journal of Science and Research (IJSR)

ISSN (Online): 2319-7064

Index Copernicus Value (2013): 6.14 | Impact Factor (2014): 5.611
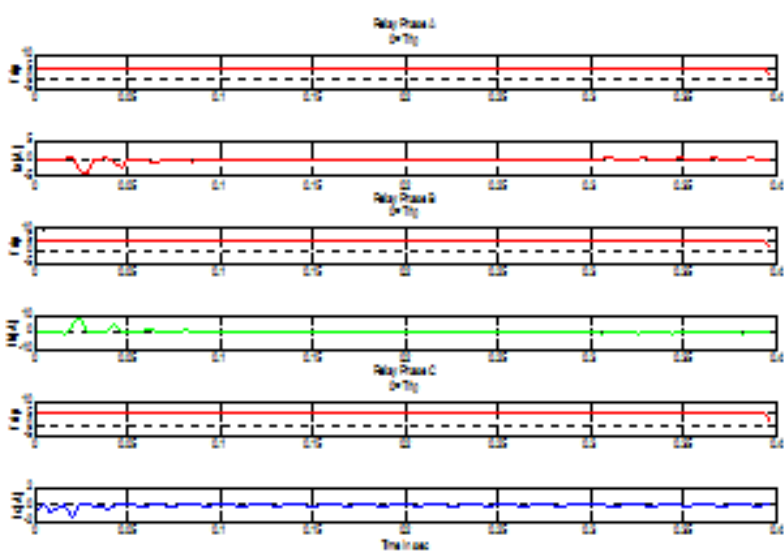

Figure 8: Relay Tripping Status for Magnetizing Inrush Current condition

Fig 7 shows magnetizing inrush current in all three phases and secondary current waveform. Here secondary current is zero during the inrush current in primary. Normal differential relay consider this condition as a fault and relay trips. From fig 8 it is clear that this proposed method differentiate inrush current from fault and there is no false tripping for any phase.

Case 3 LG fault during Magnetizing Inrush current

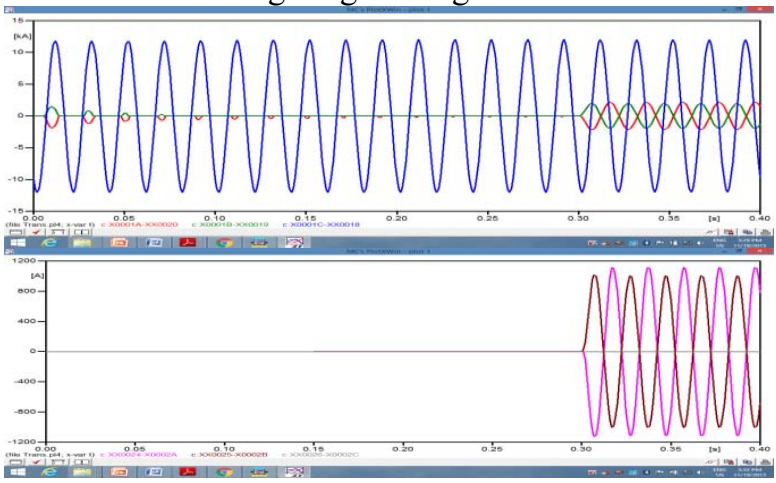

Figure 9: Input and Output Current waveform for LG fault during inrush current

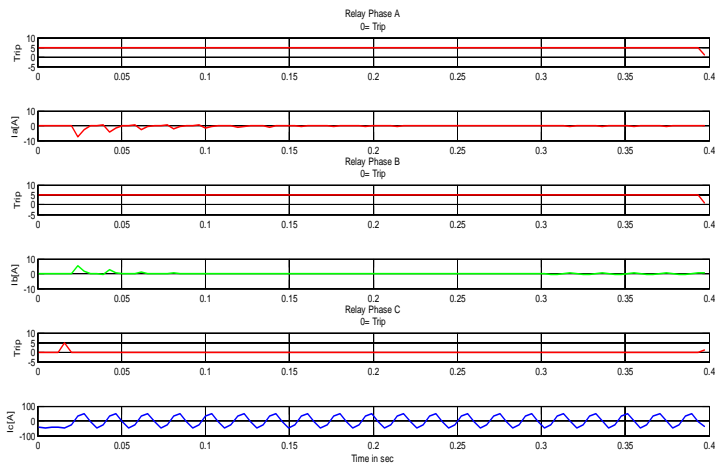

Figure 10: Relay Tripping Status for Magnetizing Inrush Current condition

This is very important condition when fault occur at the time of energisation of transformer then relay should respond very fast and accurately. Fig 9 shows fault current in phase c which is very high and inrush current for phase a and b. fig 10 shows relay tripping status in which relay for faulty phase c gets tripped in about $10 \mathrm{~ms}$, Which is desired in this condition.
Case 4 secondary LG fault, Loaded

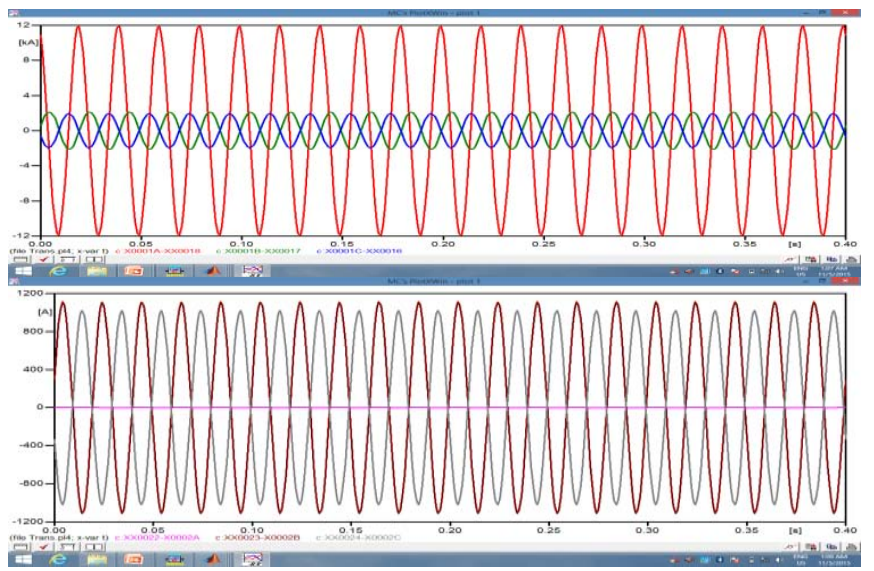

Figure 11: Input and Output Current waveform for LG fault on phase $\mathrm{A}$
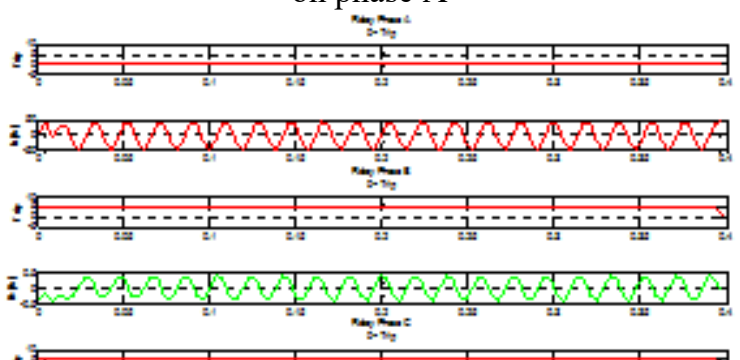

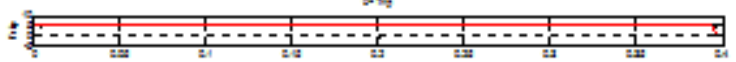

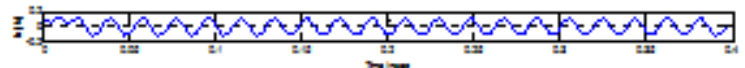

Figure 12: Relay Tripping Status for LG fault in Phase A

Fig 11 shows input and output current waveform for LG fault in phase A. here current is very high in primary side for faulty phase and other two phases have very small amount of current. Fig 12 shows tripping status where relay of phase a gets tripped.

Case 5 Secondary LL fault, Loaded

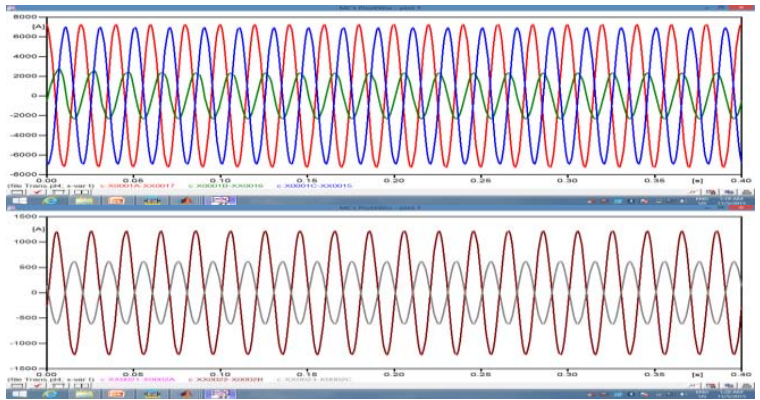

Figure 13: Input and Output Current waveform for LL fault Between phase A and C 


\section{International Journal of Science and Research (IJSR)}

ISSN (Online): 2319-7064

Index Copernicus Value (2013): 6.14 | Impact Factor (2014): 5.611

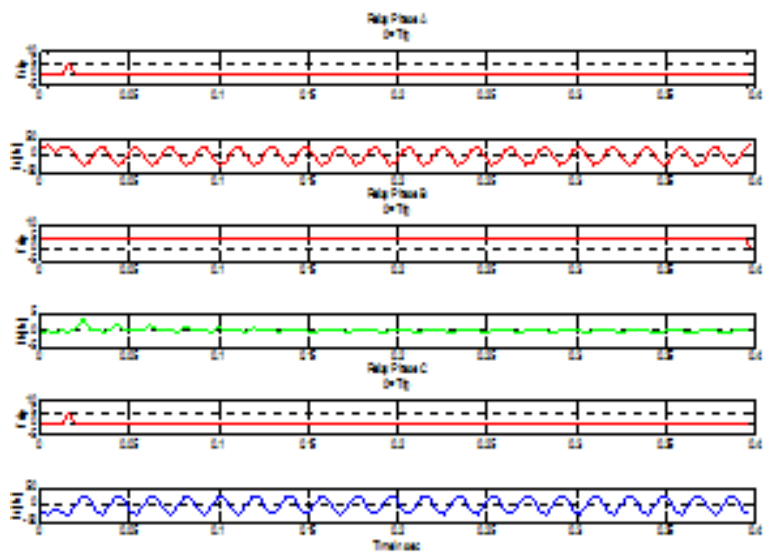

Figure 14: Relay Tripping Status for LL fault between Phase A \& C

In this case there is line to line fault between phase a and c so current in these two phases are very high which causes different relay to operate as shown in fig 14.

Case 6 Secondary LLLG fault, Loaded
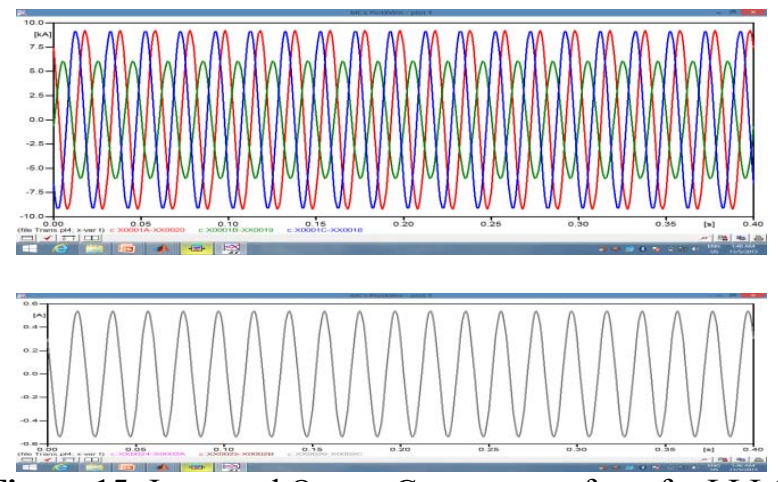

Figure 15: Input and Output Current waveform for LLLG fault
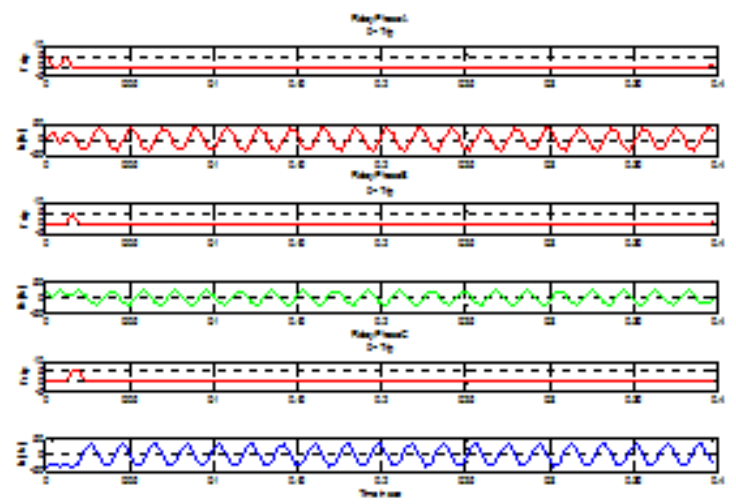

Figure 16: Relay Tripping Status for LLLG fault

This is most severe fault in power system and very rare. Fig. 15 shows current in all phase are very high in primary side secondary current is almost same in all phases. Fig. 16 shows tripping status of relay for three phase to ground fault in which relays for all the phases gets tripped.

As can be seen, relay does not give tripping response at the time of occurrence of magnetizing inrush current and when different internal faults occur, with inrush currents in different phases simultaneously then it works and very fast tripping happens in almost 10-30 ms.

\section{Conclusion}

In this paper, a new approach is proposed in order to recognize and differentiate fault currents from inrush current. This proposed system is very useful and advantageous for the prevention of false tripping of Differential Protection. In addition to suitable accuracy, the proposed method can discriminate fault from inrush current quickly, less than a quarter a cycle after the disturbance. Wavelet transform breaks the signal in time- frequency domain, with this kind of analysis, inrush and fault currents can be separated very easily since the distribution of energy in frequency and time domain for these two currents is very different. This proposed method is very reliable, easy method which can be used in differential protection of three phase power transformers.

\section{References}

[1] Jawad Faiz and S. Lotfi-Fard, “ $A$ Novel Wavelet-Based Algorithm for Discrimination of Internal Faults from Magnetizing Inrush Currents in Power Transformers", IEEE Transactions On Power Delivery, Vol. 21, No. 4, October 2006

[2] Jitendra Singh Chandra, Amit Goswami, "Differential Protection of Three Phase Power Transformer Using Wavelet Packet Transform", International Journal of Engineering Sciences \& Research Technology

[3] S. A. Saleh and M. A. Rahman, "Modeling and Protection of a Three-Phase Power Transformer Using Wavelet Packet Transform", IEEE Transactions On Power Delivery, Vol. 20, No. 2, April 2005

[4] Saleh A. Saleh Benjamin Scaplen, and M. Azizur Rahman, "A New Implementation Method of WaveletPacket-Transform Differential Protection for Power Transformers", IEEE Transactions On Industry Applications, Vol. 47, No. 2, March/April 2011

[5] Mukesh Nagpal, P. Kundur et. al.," Assessing and Limiting Impact of Transformer Inrush Current on Power Quality:, IEEE Transactions On Power Delivery, Vol. 21, No. 2, April 2006

[6] Y. Najafi Sarem, E. Hashemzadeh and M.A. LayeghTransformers Fault Detection Using Wavelet Transform, IJTPE Journal, March 2012 Issue 10 Volume 4 Number 1 Pages $17-26$

[7] Adel Aktaibi, M. A. Rahman, "Wavelet Packet Transform Algorithm Based Differential Protection of 3 phase Power Transformers"

[8] S. A. Saleh, and M. A. Rahman- Real-Time Testing of a WPT-Based Protection Algorithm for Three-Phase Power Transformers, IEEE Transactions On Industry Applications, Vol. 41, No. 4, July/August 2005

[9] M. M. Eissa- A Novel Digital Directional Transformer Protection Technique Based on Wavelet Packet, IEEE Transactions On Power Delivery, Vol. 20, No. 3, July 2005

[10] Adel A. Obed, Majed A. Alwan and Waad N. Taboor- A Wavelet Packet Transform-Based Technique for the Discrimination of Inrush Currents from Faults in ThreePhase Transformer, Journal of Basrah Researches ((Sciences)) Volume 37. Number 4 A / 15 August ((2011)) 1-14. 


\section{International Journal of Science and Research (IJSR) \\ ISSN (Online): 2319-7064}

Index Copernicus Value (2013): 6.14 | Impact Factor (2014): 5.611

\section{Author Profile}

Jitendra Singh Chandra was born in Kaneti, Sakti, Chhattisgarh, India on $4^{\text {th }}$ March 1989 . He graduated with B.E. Degree in Electrical \& Electronics Engineering from Government Engineering College Raipur, Chhattisgarh, India in the year 2010. Received post graduate diploma in T \& D form CBIP, New Delhi, India. Currently, $\mathrm{He}$ is pursuing M.Tech. from Disha Institute of Management and Technology, Raipur, Chhattisgarh, India. His field of interest includes Electrical Power system, Protection, Operation and maintenance of Transmission And Distribution system, Power Electronics.

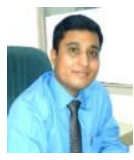

Amit Goswami was born in Raipur, Chhattisgarh, India on 23rd February 1984. He graduated with B.E. Degree in Electrical Engineering from Rungta College of Engineering and Technology, Bhilai, Chhattisgarh, India in the year 2006. He received M.E. Degree in Power System from Shri Shankaracharya College of Engineering and Technology, Bhilai, Chhattisgarh, India. His field of interest includes Electrical Machines, Power System Analysis, Power System Protection and Switchgear. 